\title{
Modeling of Tree Volume against Crown Area for Dalbergia sissoo Stand in Hariyarpur Community Forest of Nepal
}

\author{
Santosh Ghimire ${ }^{1 *}$, Jeetendra Gautam ${ }^{2}$ \\ ${ }^{1,2}$ Agriculture and Forestry University, Faculty of Forestry, Hetauda, Nepal \\ *Corresponding Author (Email: ghimiresantosh20520222@gmail.com)
}

How to cite this paper: Ghimire, S. and Gautam, J. (2019). Modeling of Tree Volume against Crown Area for Dalbergia sissoo Stand in Hariyarpur Community Forest of Nepal. Grassroots Journal of Natural Resources, 2(3): 1-15. Doi: https://doi.org/10.33002/nr2581.6853.02031

Received: 03 June 2019

Reviewed: 21 July 2019

Provisionally Accepted: 31 July 2019

Revised: 15 August 2019

Finally Accepted: 30 August 2019

Published: 30 September 2019

Copyright (C) 2019 by author(s) and

The Grassroots Institute.

This work is licensed under the Creative Commons Attribution International License (CC BY 4.0).

http://creativecommons.org/licenses/by/4.0/
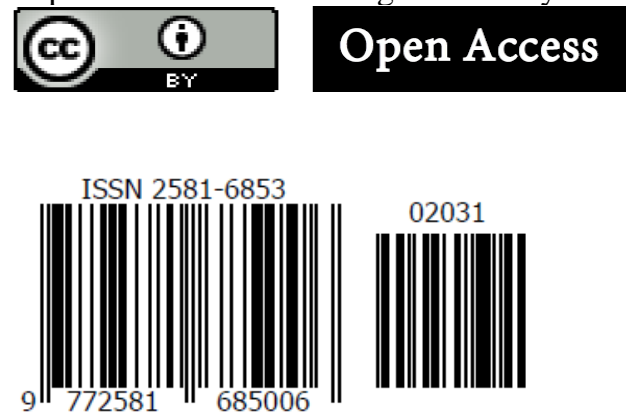

\begin{abstract}
Complex geographical features and forest inventory methods are more time consuming, expensive and labourintensive. Therefore, development of model equation is important. To conduct this study, systematic sampling technique was adopted with 5\% sample intensity. Tree volume was calculated from field inventory and crown area calculated from Google Earth imagery. RProgramme was used for data analysis and various tests (ANOVA, F-test and Z-test) were done for model validation. The best-fitted model of tree volume against the crown area for Dalbergia sissoo stand was obtained (Volume $=\mathrm{A}^{*}$ Crown^2 $+\mathrm{B} *$ Crown $+\mathrm{C}$ ) using Root Mean Square Error (RMSE) value 0.054 and Coefficient of Determination $\left(\mathrm{R}^{2}\right)$ value 0.9125153 . The trend of this model exhibits that volume distribution varied in direct proportion to the extent of crown cover area up to certain limit. With further increase in extent of crown area, the volume distribution shows an inverse relationship. This model can be used to predict the tree volume for Dalbergia sissoo stand of 15-20 years of age. This model, in turn, will be helpful for managers, planners, foresters and decision-makers for better management and utilization of Dalbergia sissoo forest.
\end{abstract}

\section{Keywords}

Remote Sensing; Modeling; Forest inventory; RProgramme 
Doi: https://doi.org/10.33002/nr2581.6853.02031

\section{Introduction}

Remote sensing technology has dramatically played a crucial role to measure forest biophysical characteristics (Popescu, 2002). Many of the information related to the crown cover area, ground topography and vegetation parameters such as height, tree density, and crown width are provided by the remotely sensed data, which forms a basic element to modeling activities. Remote sensing technology combines both surface elevations and accurate planimetric coordinates to develop linear and non-linear equation which can assist in identification of single trees or a group of trees to extract various measurements (Popescu, 2002). The remote sensing technology together with field inventory data are increasingly gaining the interest of the numerous organizations that are involved in the forest inventory activities. For example, the Reducing Emissions from Deforestation and Forest Degradation (REDD+) mechanism highlights the need for forest resource inventories and has widened the use of their results (GOFC-GOLD, 2011). The tasks of Forest Resource Assessment (FRA) in Nepal is an example of an action that operates based on information obtained from both conventional field inventories and remote sensing materials.

The importance of carbon sequestration and reducing emissions from deforestation and forest degradation has accelerated new demands for the country-level forest inventories (GOFC-GOLD, 2011). Similarly, forest degradation has resulted in the specific need for up-to-date, accurate and multifunctional models for predicting not only the above-ground but also the below-ground components of tree biomass (GOFC-GOLD, 2011). The models for predicting stem volumes, merchantable volumes of trees and various components of tree biomass require data collection through surveys (Eerikainen, 2010).

Analysis techniques, models and other statistical tools allow for the rapid evaluation of extensive voluminous data sets. So, an accurate prediction of tree dimensions has become possible. It is easy to measure the parameters such as, diameter and age with simple instruments. However, literature has shown that other variables can also help improve the reliability of tools like growth and yield models. Among them, crown size is one such parameter to estimate tree growth (Singer and Lorimer, 1997).

Aerial photograph and photo interpretation have long depended on relationships between crown width and stem diameter for stand inventories (Gill, Biging and Murphy, 2000), while others have used crown width to estimate fuel loading (Menwig, Miller and Budy, 1979). Numerous measures of tree competition depended on crown width to adjust for tree-to-tree interactions (Hatch, Gerrard and Tappeiner, 1975).

Sissoo (Dalbergia sissoo) belongs to the family Leguminacea. Sissoo naturally occurs throughout the sub-Himalayan tract and outer Himalayan valley from the Indus to Assam. It is extensively planted in different countries like Nepal, India, Bhutan, Bangladesh, Myanmar, Malaysia, Pakistan and Afghanistan and in tropical to sub-tropical Africa (Chourasia, 2012). This species has a great value for furniture, joinery and carving and the foliage is used as fodder. Because of its natural hardness, fast growth and high timber value, it has been mostly used in afforestation and reforestation both in community forestry and agroforestry programmes (Chourasia, 2012).

Maximum land of Nepal is covered by Siwalik hills and mountain region. It is very difficult to carry out forest resources inventory in Siwalik hills and mountain region due to complex 
geographical feature and the rugged topography. So, forest inventory has become more time consuming, expensive and labour intensive. Developing, evaluating and adapting new regression model equations are critically important in economic analysis, carbon stock estimation and forest management. In short time, equation helps to identify growth stock that relates to Dalbergia sissoo of certain age all over the country.

This study has successfully developed an equation model based on tree volume against crown area for Dalbergia sissoo using remotely sensed data. The focus was on a single species with certain age stands i.e. 15-20 years of age in plantation site, because it would be easy to develop regression model in the even aged forest.

\section{Materials and Methods}

To conduct this study, systematic sampling with 5 percent sampling intensity was adopted. A circular plot size of 500,100, 25 and $1 \mathrm{~m}^{2}$ were taken for trees, poles, saplings and seedlings, respectively. The height and diameter at breast height $(\mathrm{DBH})$ of each tree was measured for volume estimation using the following formulae:

Volume $=\pi(\mathrm{DBH})^{2} / 4 *$ height $*$ form factor

Remotely sensed data (Google Earth) were used for identification and calculation of crown cover area of tree. Over-storey visible crown cover was taken and under-storey crown cover was omitted as they were not visible. Altogether, 12 sample plots were selected for plot layout. 50 trees were used to fit the models, in which 29 trees were used from sample plot and remaining 21 trees were selected randomly outside the plot. 50 trees were used for model validation. All trees were selected randomly outside sample plot according to the guidelines of random table.

\section{Data Analysis:}

The data was handled with R-script in R-programme to generate different models. Different linear and non-linear models were used to fit the tree volume against crown area for Dalbergia sissoo stand. 10 model equations were tested to identify regression model on the basis of $\mathrm{R}^{2}$ value. Analysis of Variance (ANOVA) test was done to select the best fitted model. F-test followed by Z-test was performed to determine the field accuracy of the best selected model for volume estimation.

\section{Results}

\section{Volume Distribution in the Forest}

The boxplot in figure 1 below shows that tree volume extends from $0.034 \mathrm{~m}^{3}$ to $0.69 \mathrm{~m}^{3}$. The mean value of 50 tree volume was $0.2878 \mathrm{~m}^{3}$. The black line shown in boxplot indicates medium value of 50 tree volume which is about $0.3 \mathrm{~m}^{3}$. 


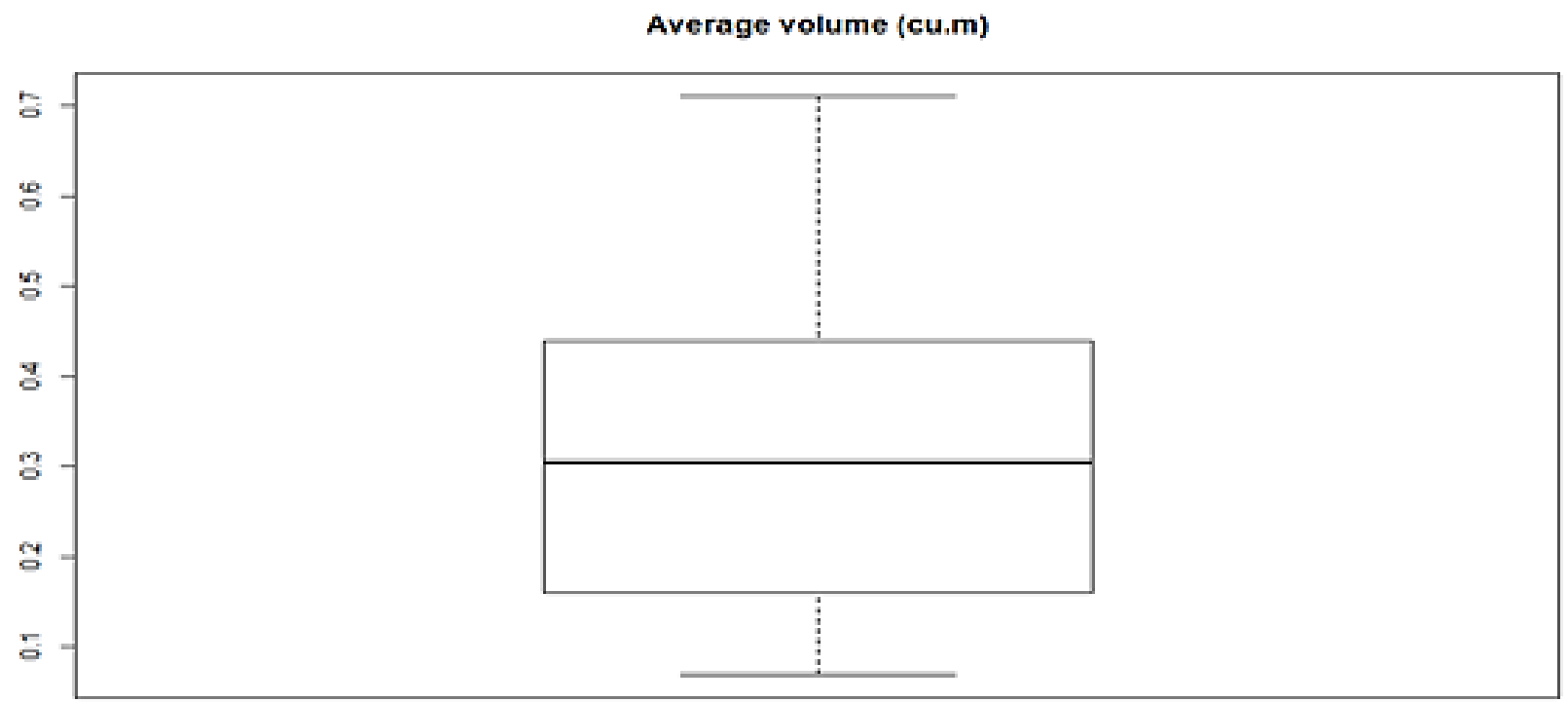

Figure 1: Average volume of 50 sample trees

\section{Extent of Average Crown Covers}

The boxplot shown in figure 2 depicts tree crown area extends from $4.51 \mathrm{~m}^{2}$ to $25 \mathrm{~m}^{2}$. The mean value of 50 tree crown area was $10.423 \mathrm{~m}^{2}$. The black line shown in boxplot indicates medium value of 50 trees crown area which is about $10 \mathrm{~m}^{2}$.

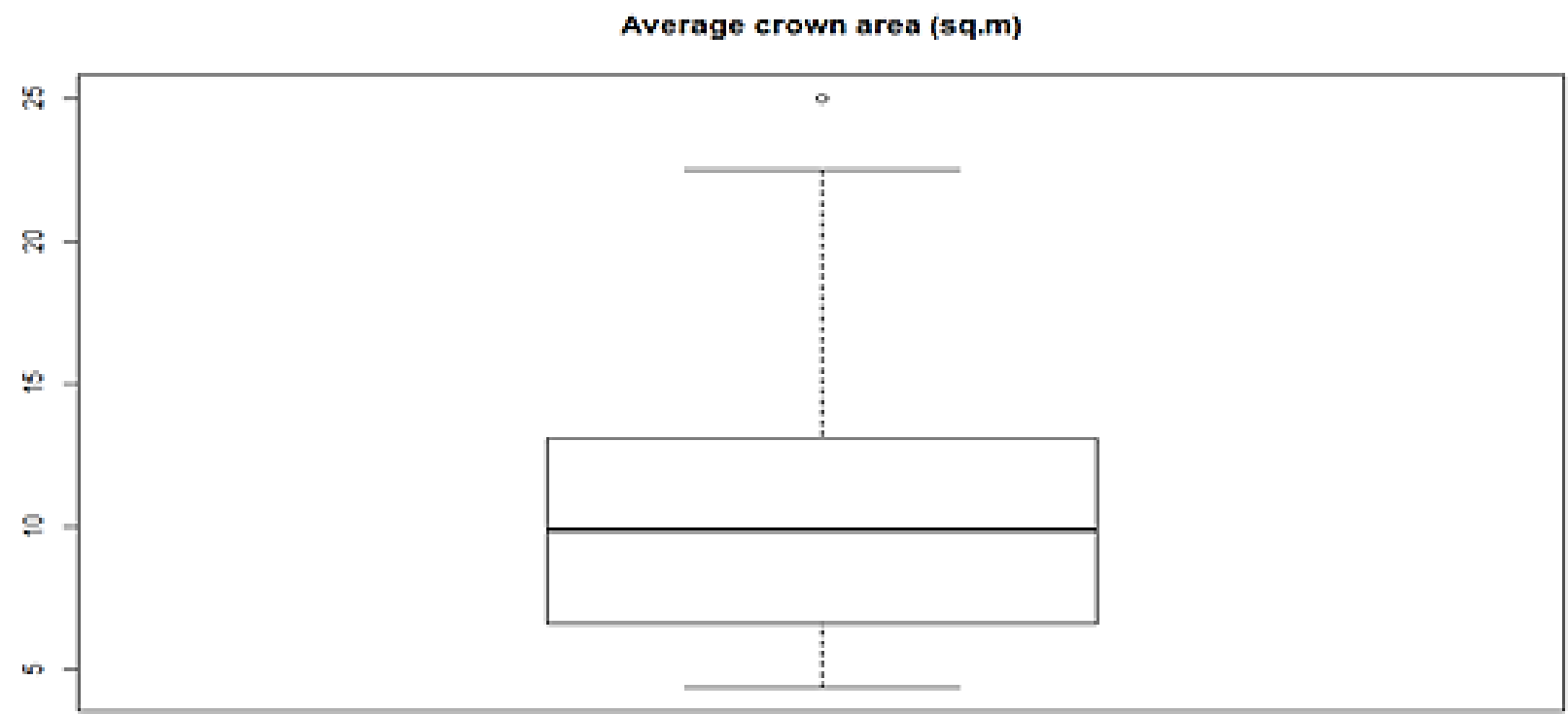

Figure 2: Average crown area of 50 sample trees

Figure 3 represents the distribution of trees, sample plot and crown cover in study area. The tree inside the sample plot helps to fitted model equation and trees outside the sample plot helps in validation of that equation. 


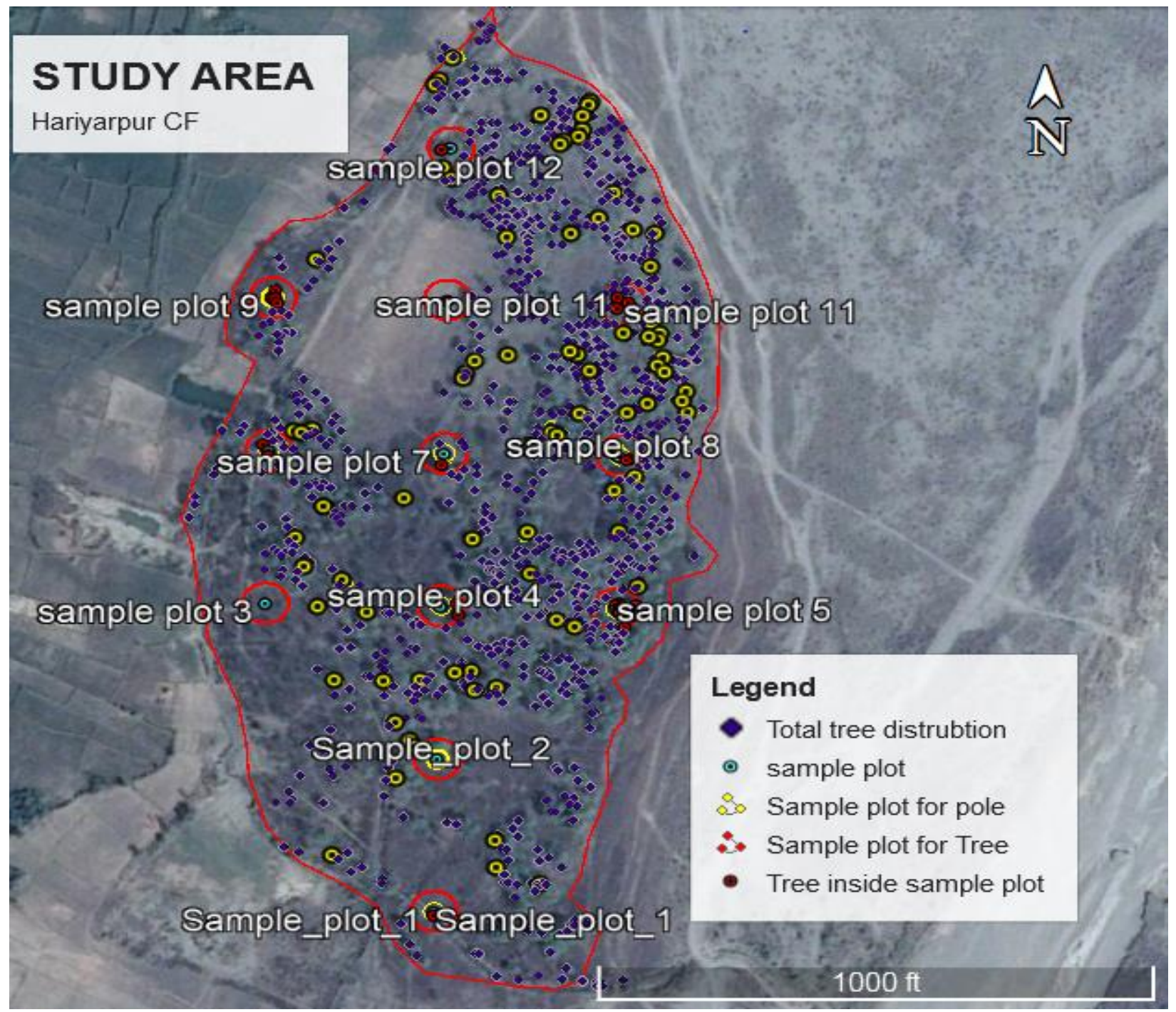

Figure 3: Sample plot, tree distribution and crown cover area.

\section{Model Fitting and Evaluation}

Ten tree volume models were selected to connect tree volume against crown area for Dalbergia sissoo stand. Tree volume was calculated from diameter at breast height $(\mathrm{DBH})$ and height that was taken from field and crown area was taken by measuring upper most visible individual crown using Google Earth imagery. Different linear and non-linear (logarithm and exponential) function was used to fit the equations with R-studio project. Different starting values were used for the parameters to ensure that a global minimum was achieved.

The best function was selected on the basis of two statistical criteria: Root Mean Square Error (RMSE) and the adjusted Coefficient of Determination $\left(\mathrm{R}^{2}\right)$, where $\mathrm{A}, \mathrm{B}, \mathrm{C}, \mathrm{D}$ are the model parameters. The detailed information of model is illustrated in figure 4 to 13 and table 1. 


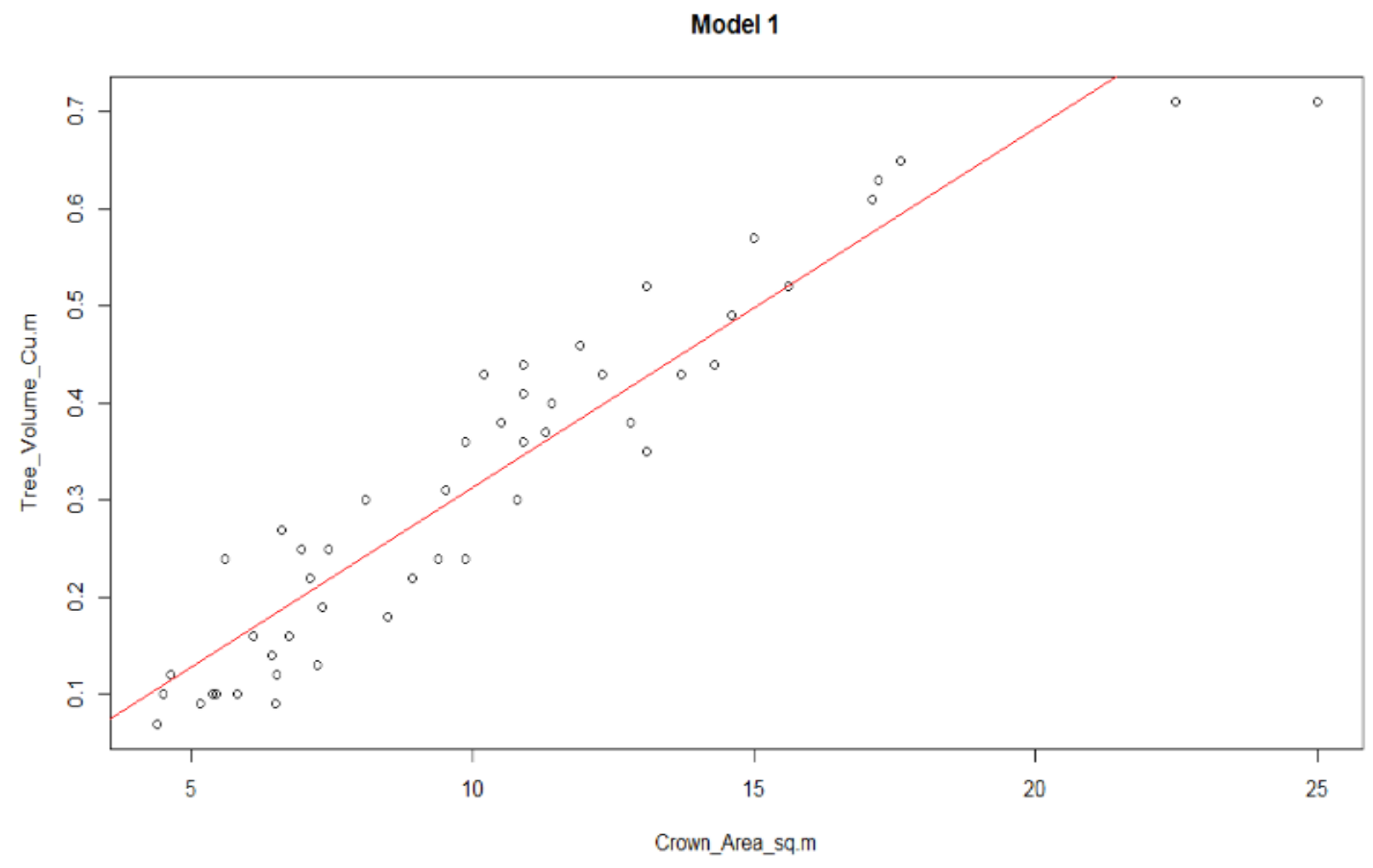

Figure 5: Graphical representation of Model 1

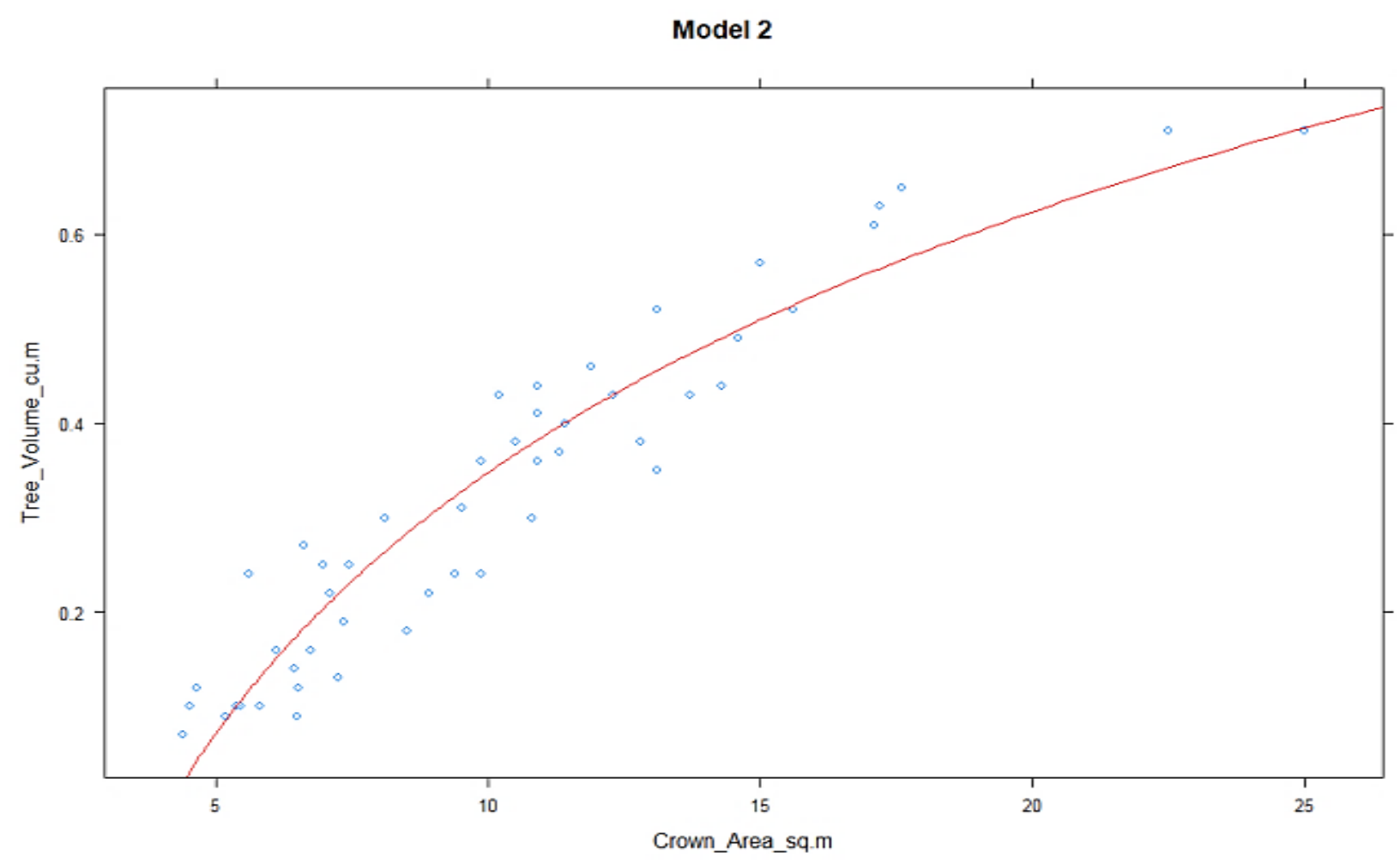

Figure 4: Graphical representation of Model 2 


\section{Model 3}

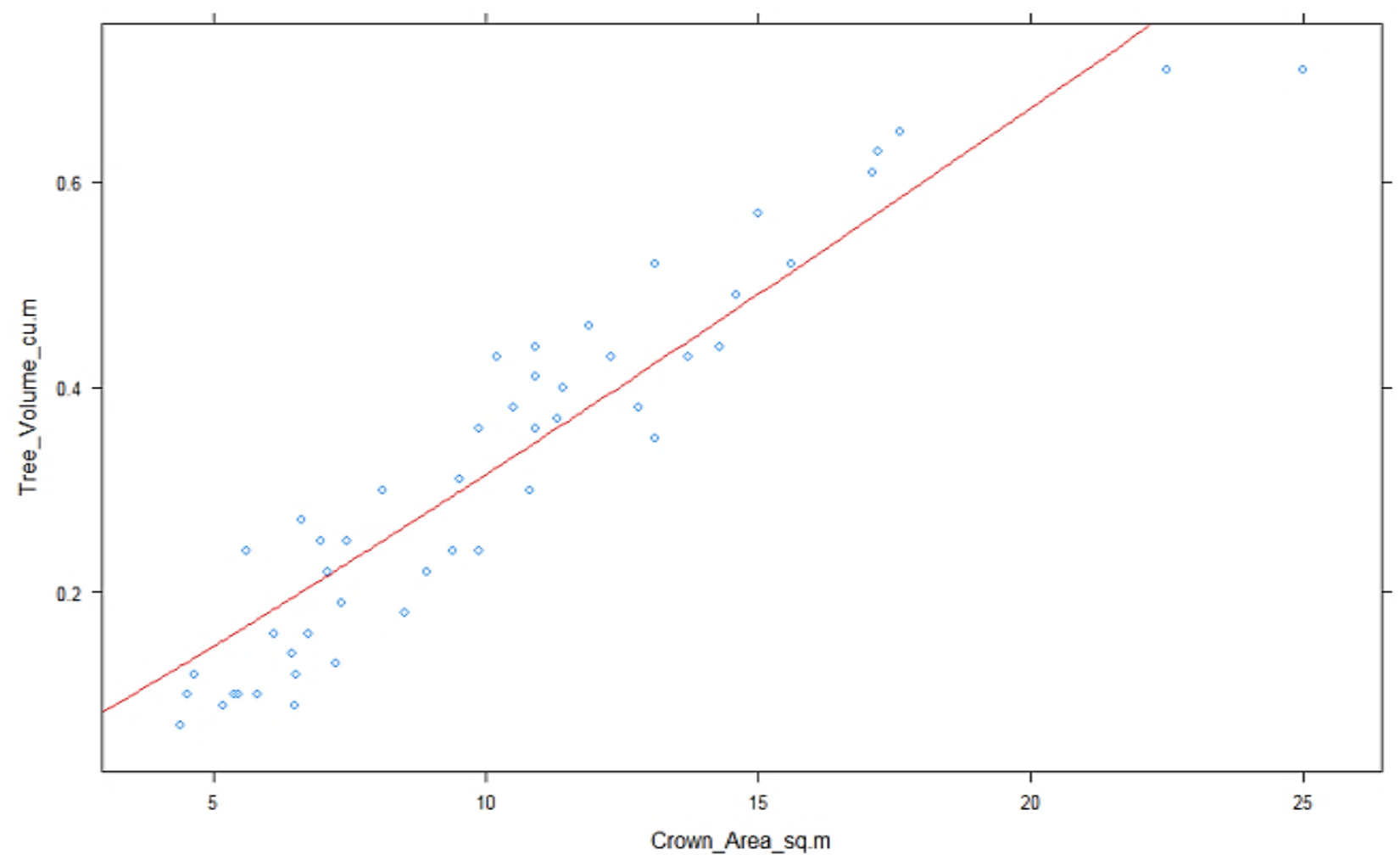

Figure 6: Graphical representation of Model 3

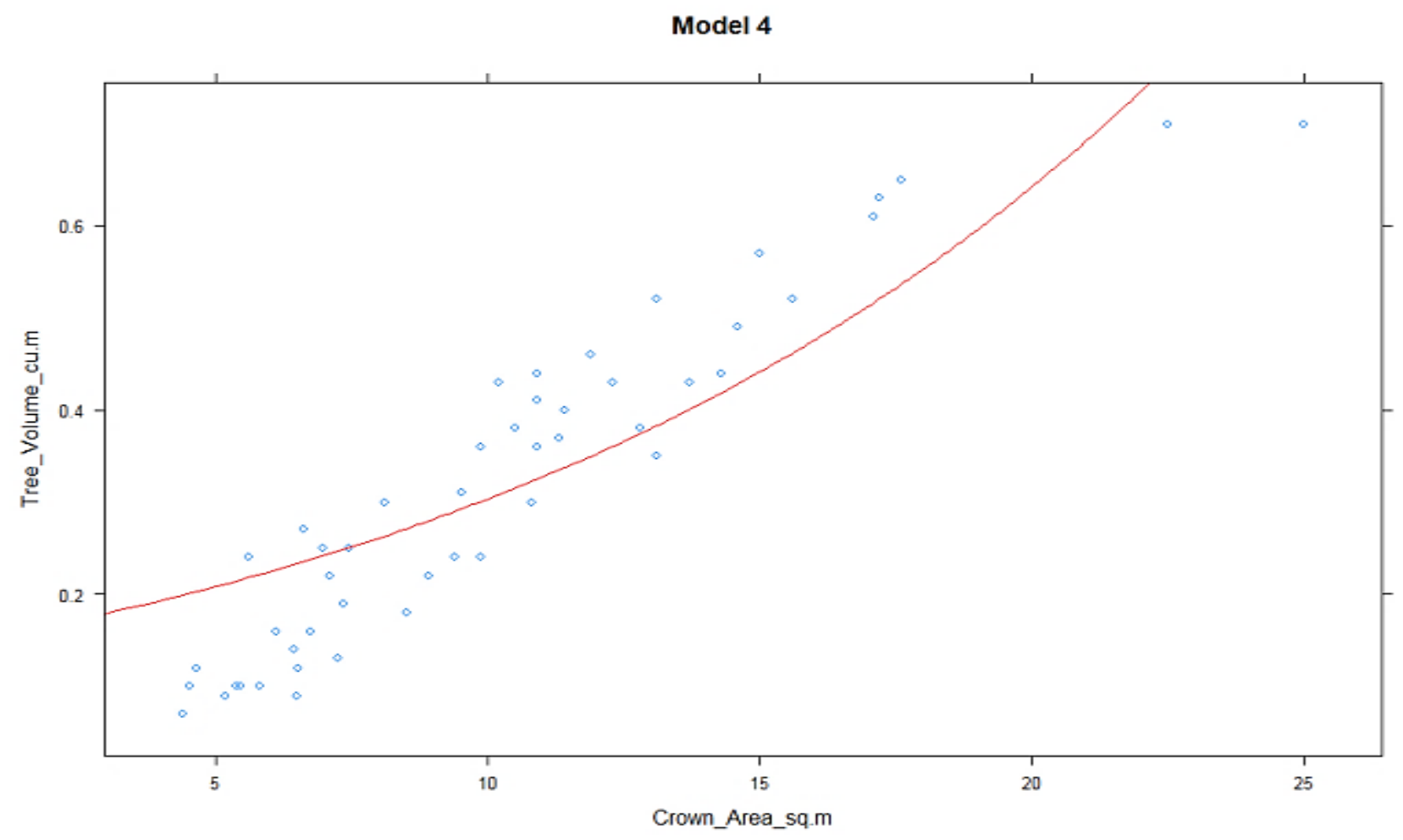

Figure 7: Graphical representation of Model 4 


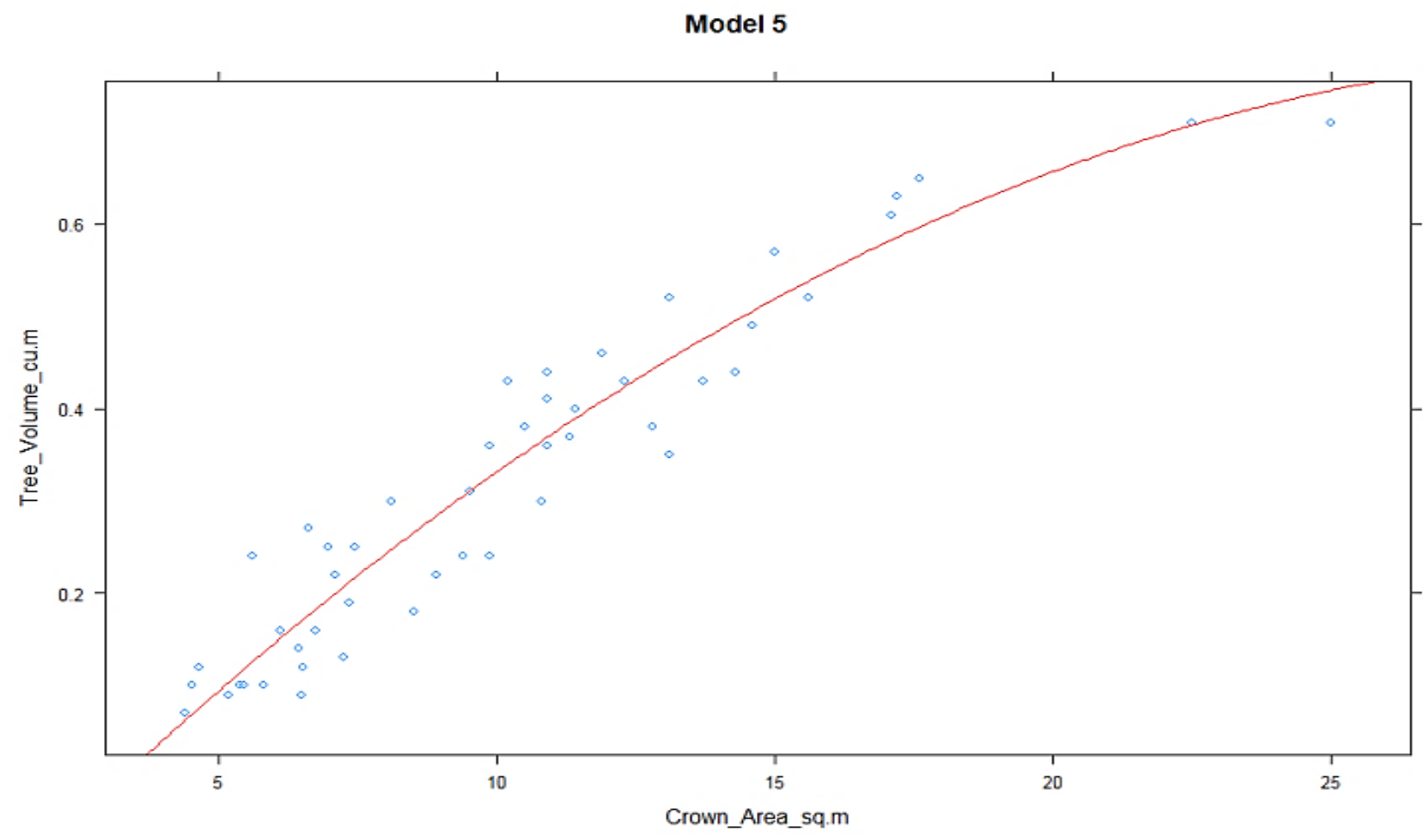

Figure 8: Graphical representation of Model 5

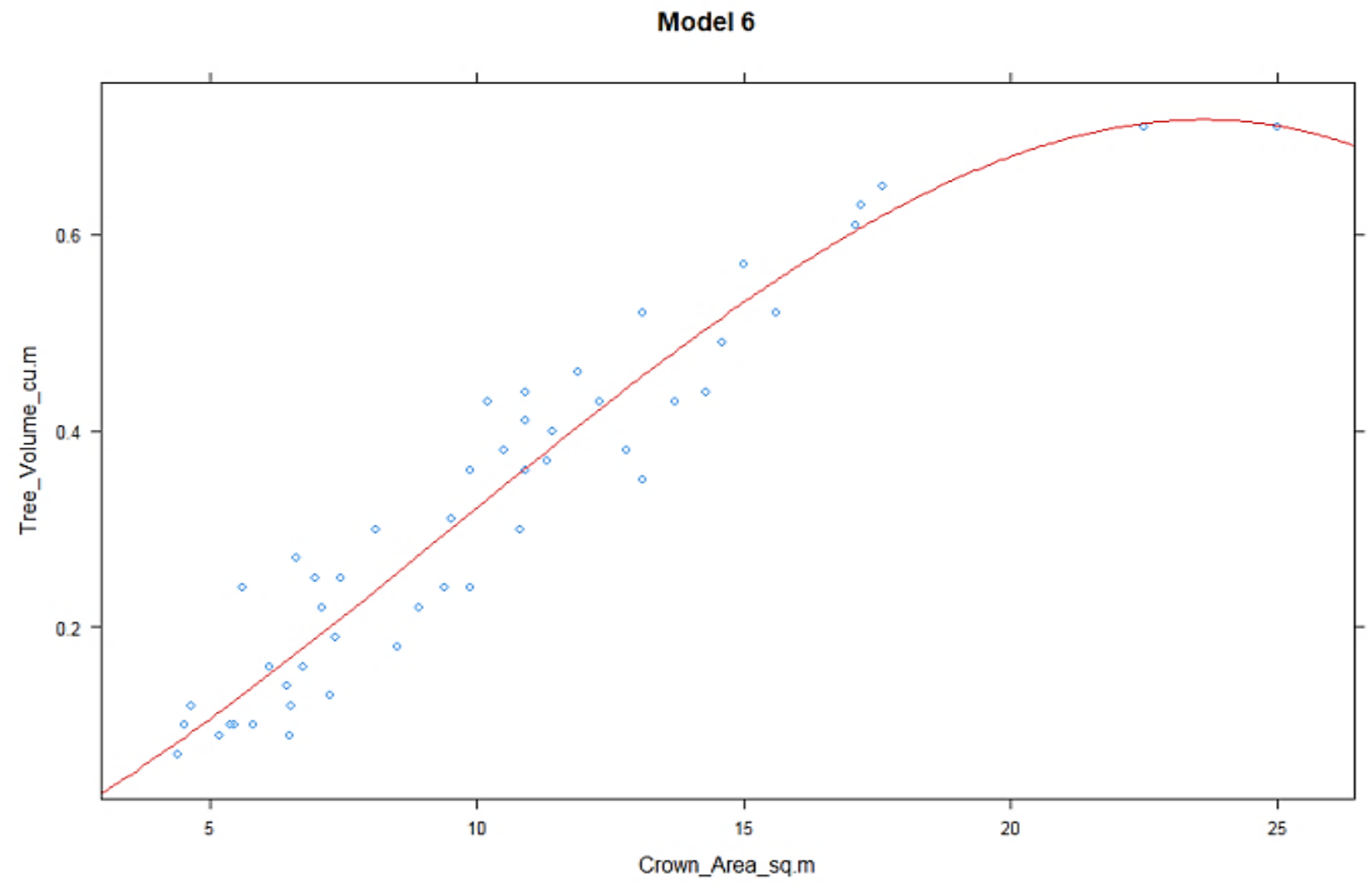

Figure 9: Graphical representation of Model 6 


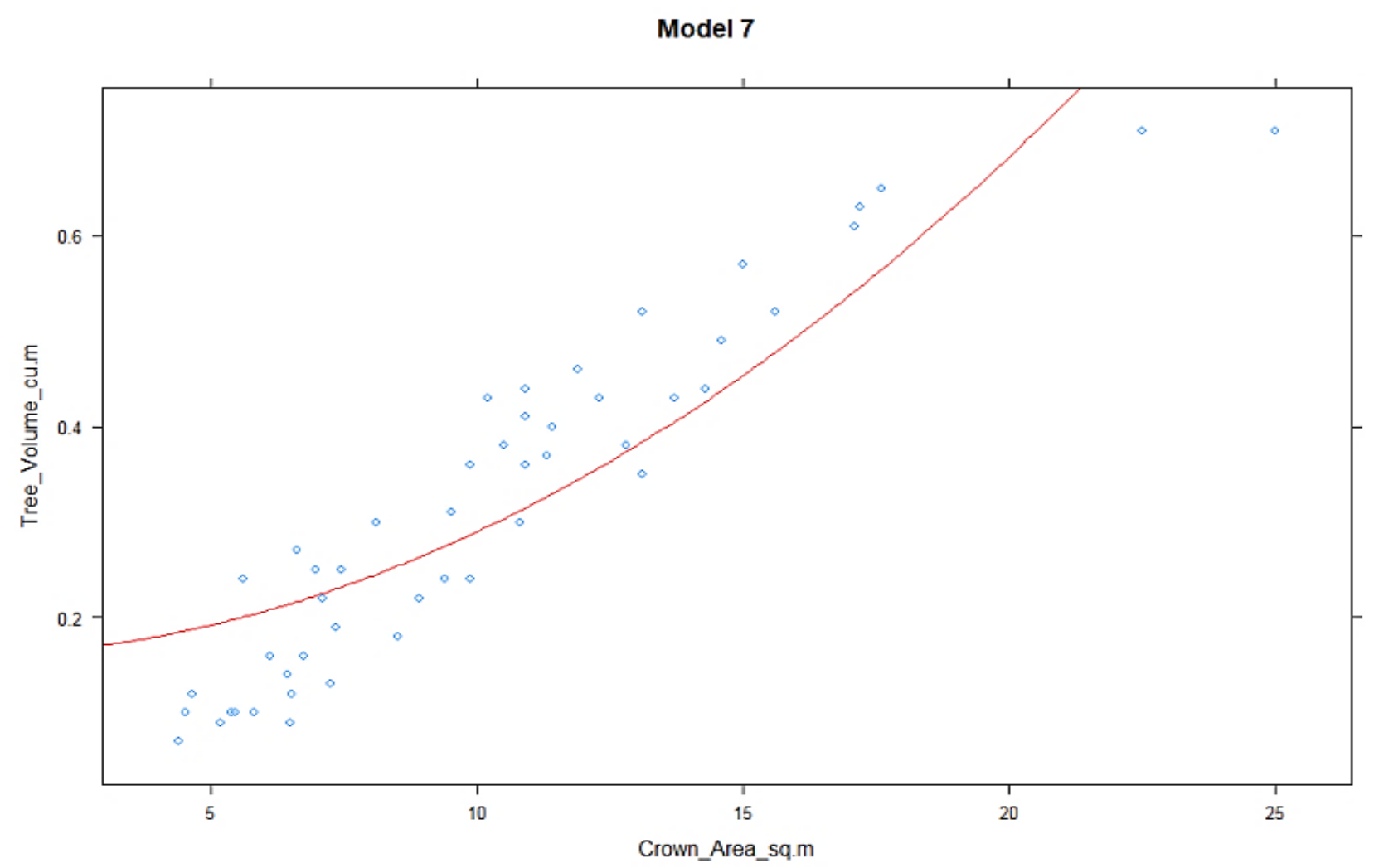

Figure 10: Graphical representation of Model 7

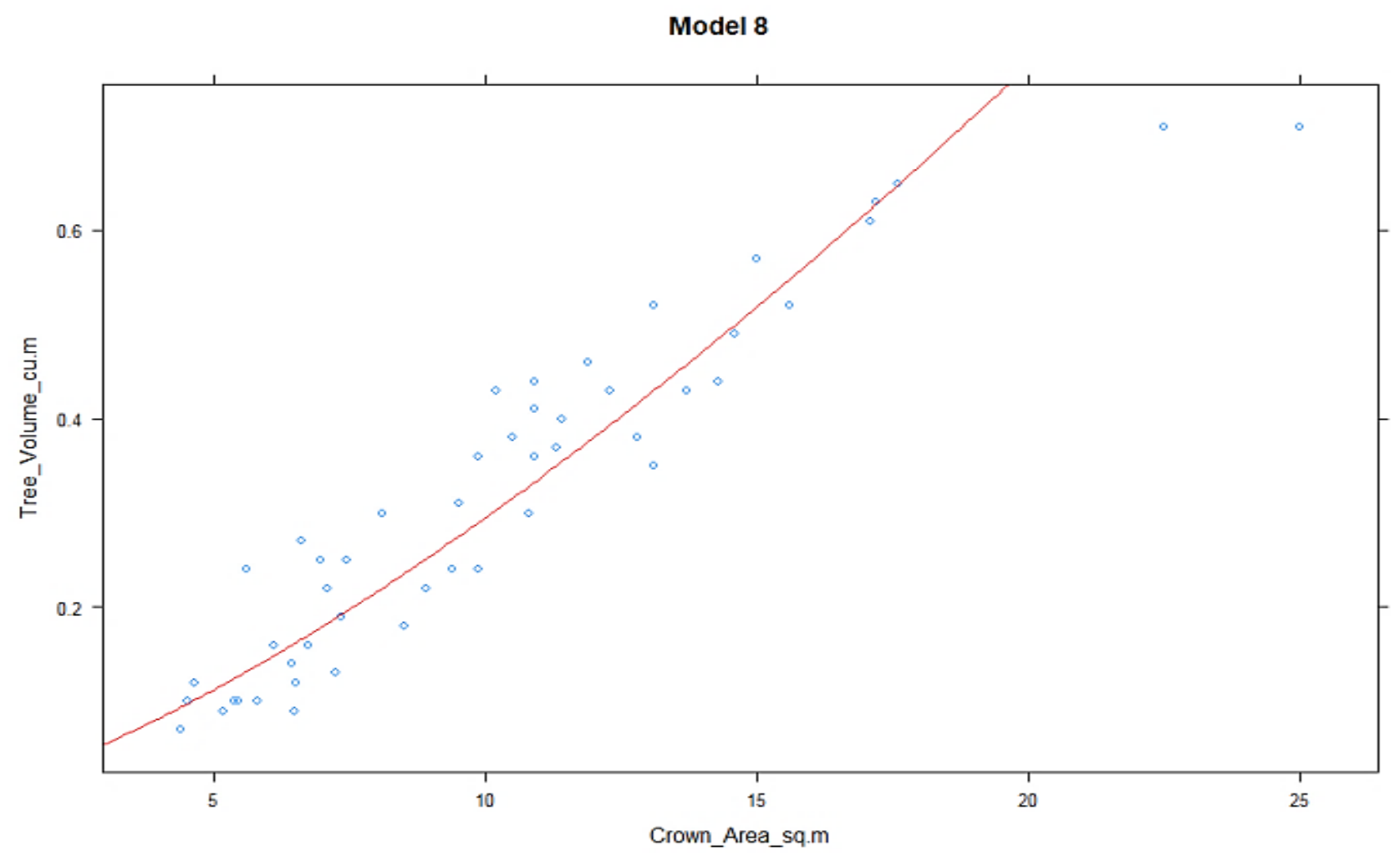

Figure 11: Graphical representation of Model 8 


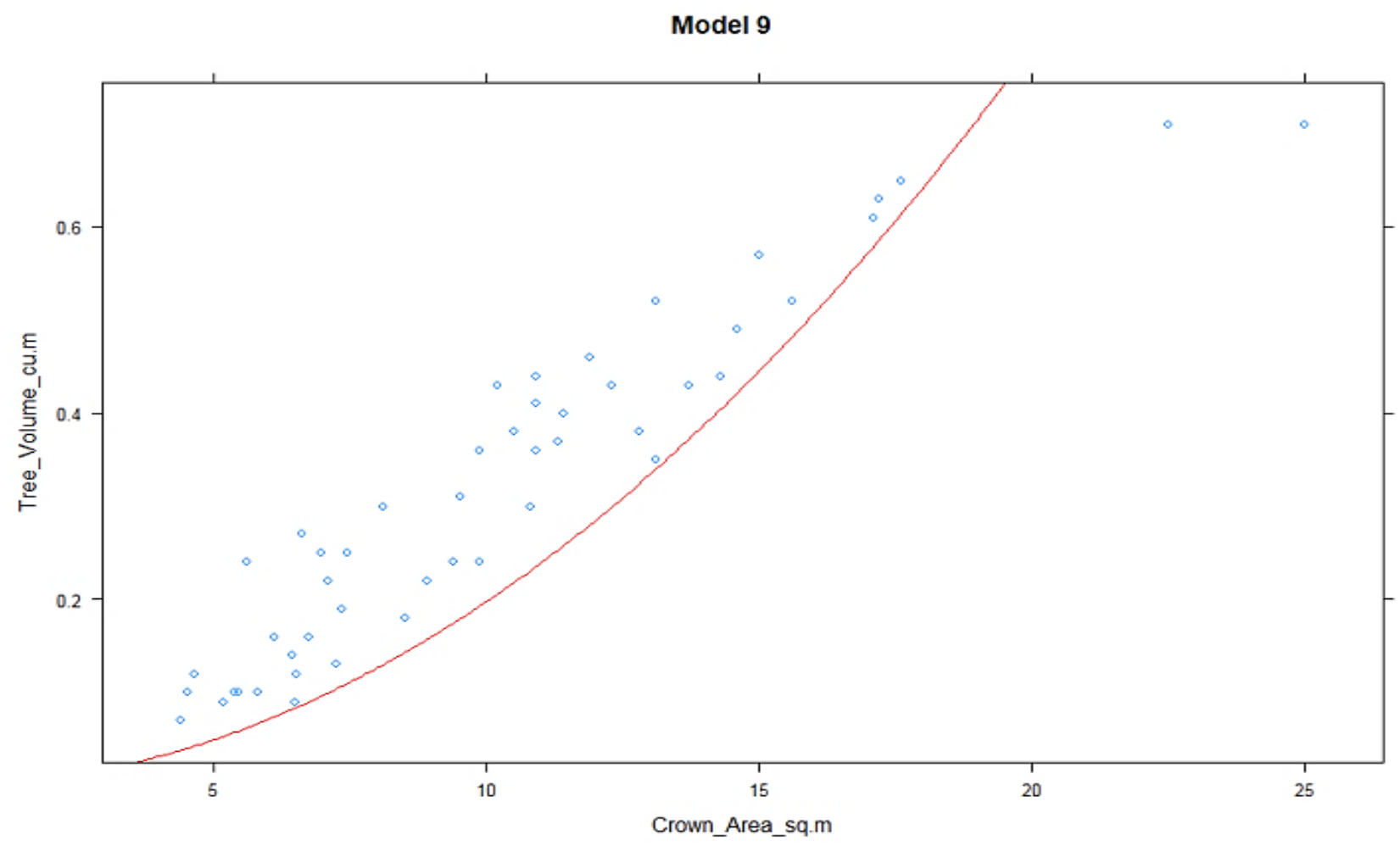

Figure 12: Graphical representation of Model 9

Model 10

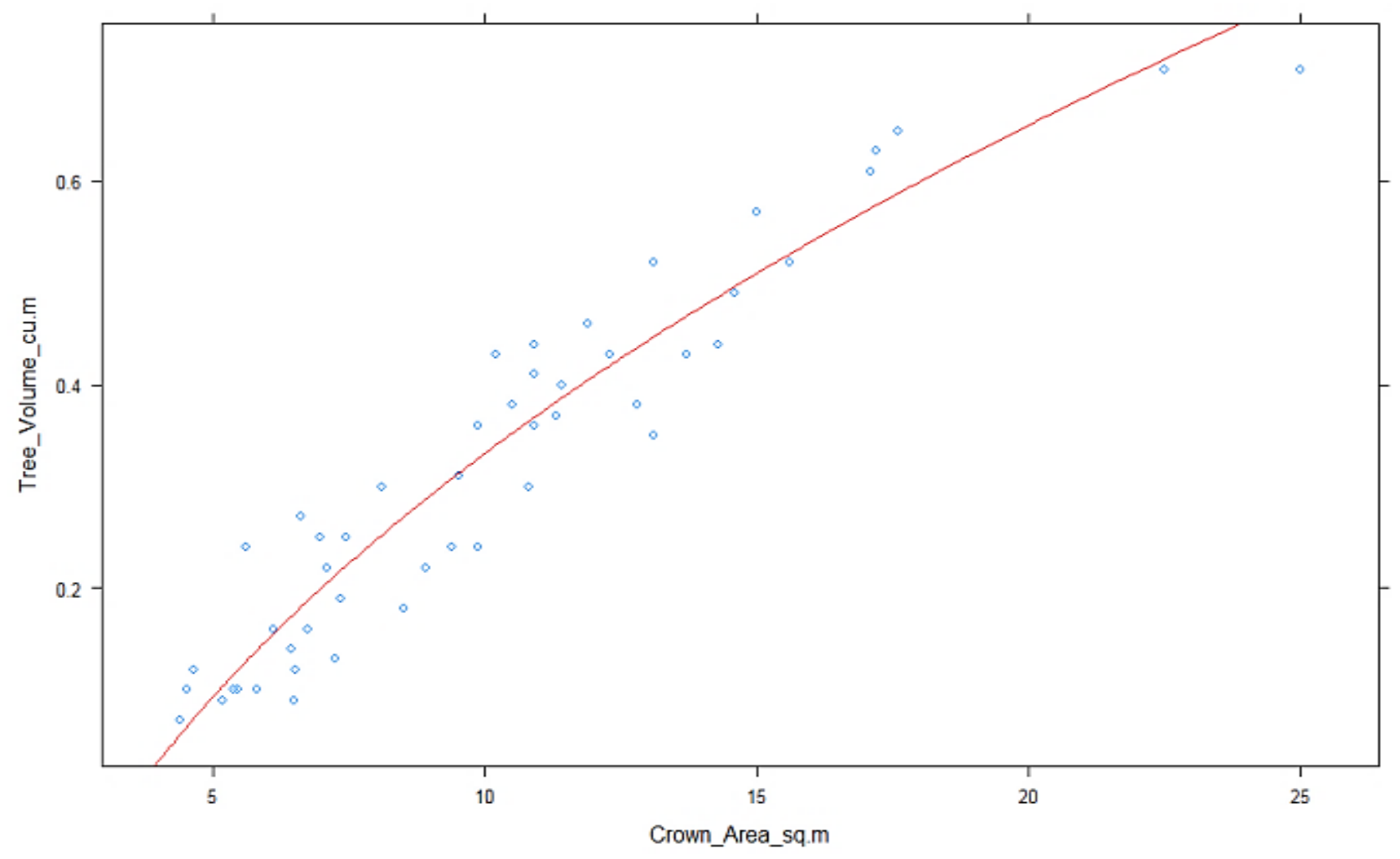

Figure 13: Graphical representation of Model 10 
Table 1: Summary of 10 Models

\begin{tabular}{|c|c|c|c|c|c|c|c|}
\hline $\begin{array}{l}\text { Model } \\
\text { No. }\end{array}$ & Model equation & A & B & $\mathrm{C}$ & $\mathrm{D}$ & RMSE & $\mathrm{R}^{2}$ \\
\hline 1 & Vol. $=\mathrm{A}^{*}$ Crown $+\mathrm{B}$ & 0.03702637 & -0.05677883 & & & 0.06098 & 0.8860898 \\
\hline 2 & $\begin{array}{l}\text { Vol. }=\mathrm{A} * \log (\text { Crown }) \\
+\mathrm{B}\end{array}$ & 0.3977115 & -0.5674725 & & & 0.05838 & 0.8955862 \\
\hline 3 & Vol. $=\mathrm{A}^{*}$ Crown $^{\wedge} \mathrm{B}$ & 0.02546819 & 1.09272958 & & & 0.06361 & 0.8760506 \\
\hline 4 & $\begin{array}{l}\text { Vol. }=\mathrm{A} * \exp ^{\wedge}(\mathrm{B} * \\
\text { Crown })\end{array}$ & 0.14360016 & 0.07487014 & & & 0.09131 & 0.7445995 \\
\hline 5 & $\begin{array}{l}\text { Vol. }=A^{*} \text { Crown }{ }^{\wedge}+ \\
\text { B }^{*} \text { Crown }+ \text { C }\end{array}$ & -0.0009909698 & 0.0622226775 & $\begin{array}{l}- \\
0.1911758 \\
529\end{array}$ & & 0.054 & 0.9125153 \\
\hline 6 & $\begin{array}{l}\text { Vol.= A*Crown`3 + } \\
\text { B*Crown^2 }^{*} \text { Crown }^{*} \\
\text { C*Crown + D }\end{array}$ & $-7.394 e-05$ & $2.106 \mathrm{e}-03$ & $2.433 \mathrm{e}-02$ & $-5.790 \mathrm{e}-02$ & 0.05338 & 0.9163323 \\
\hline 7 & $\begin{array}{l}\text { Vol. }=\text { A + B * } \\
\text { Crown^2 }\end{array}$ & 0.159477279 & 0.001308177 & & & 0.08831 & 0.7611096 \\
\hline 8 & $\begin{array}{l}\log (\text { Vol. })=A+ \\
\mathrm{B}^{*} \log (\text { Crown })\end{array}$ & -4.423747 & 1.391418 & & & 0.2428 & 0.8027454 \\
\hline 9 & Vol. $=A *$ Crown ${ }^{\wedge}$ & 0.001981936 & & & & 0.1404 & 0.3838839 \\
\hline 10 & $\begin{array}{l}\text { Vol. }=\mathrm{A}+\mathrm{B} * \text { Crown }^{\wedge} \\
\mathrm{C}\end{array}$ & -0.5887993 & 0.3403281 & 0.4327104 & & 0.05568 & 0.9070106 \\
\hline
\end{tabular}

Among ten models, $\mathrm{R}^{2}$ value of model 6 is maximum i.e. 0.9163 and residual standard error is 0.05338. Thus, most fitted equation for model 6 is as under:

Volume $=\mathrm{A}^{*}$ Crown $^{\wedge} 3+\mathrm{B}^{*}$ Crown $^{\wedge} 2+\mathrm{C}^{*}$ Crown $+\mathrm{D}$

Where,
$\mathrm{A}=-7.394371 \mathrm{e}-05$
$\mathrm{B}=2.106020 \mathrm{e}-03$
$\mathrm{C}=2.433200 \mathrm{e}-02$
$\mathrm{D}=-5.789714 \mathrm{e}-02$

The other equation nearest to model 6 or second highest Coefficient of Determination $\left(\mathrm{R}^{2}\right)$ value is model 5 which Coefficient of Determination $\left(\mathrm{R}^{2}\right)$ value is 0.9125153 and Root Mean Square Error (RMSE) is 0.054. The fitted equation for model 5 is:

\section{Selection of Best Fitted Model}

Assumed hypothesis to test significance between model 5 and model 6 is narrated as under:

Null hypothesis $\left(\mathrm{H}_{0}\right)=$ There is no significance between model 5 and model 6 equation.

Alternative hypothesis $\left(\mathrm{H}_{1}\right)=$ There is significance between model 5 and model 6 equation. 
While testing analysis of variance table between model 5 and model 6 , following results were obtained using R-studio programme:

ANOVA (Model_5, Model_6)

Model 5: Volume $(\mathrm{Vm} 3) \sim$ Crown $+\mathrm{I}\left(\right.$ Crown`2 $\left.^{\wedge}\right)$

Model 6: Volume $(V m 3) \sim$ Crown $+\mathrm{I}\left(\right.$ Crown^$\left.^{\wedge} 2\right)+\mathrm{I}\left(\right.$ Crown`3 $\left.^{\wedge}\right)$

\begin{tabular}{|ccccccc|}
\hline Model & Res. Df & RSS & Df & Sum of Square & F & $\operatorname{Pr}(>\mathrm{F})$ \\
5 & 47 & 0.13708 & & & & \\
6 & 46 & 0.13109 & 1 & 0.0059806 & 2.0985 & 0.1542 \\
\hline
\end{tabular}

There was no significance between model 5 and model 6 equation i.e. $\mathrm{P}(0.1542>0.05)$ at $95 \%$ level of confidence. Model 6 was more complex, and more parameters were used than in model 5. Therefore, model 5 was taken as best fitted model of tree volume against crown area for Dalbergia sissoo stand. Compared to other model, model 5 can measure stand variable easily and can better explain the volume, which has an obvious relationship between tree volume and crown area of Dalbergia sissoo stand.

\section{Field Verification of Model (Model Validation)}

F-test was used to check the variance between actual volume obtained from field and predicted volume that was obtained from best fitted model equation i.e. Volume $=\mathrm{A}^{*} \mathrm{Crown}{ }^{\wedge} 2+$ B*Crown $+\mathrm{C}$ at 95 percent significance level.

Assumed hypothesis to test similarity between variance of actual volume and predicted volume is as under:

Null hypothesis $\left(\mathrm{H}_{0}\right)=$ the variance ratio of actual volume from field and predicted volume from model was equal to 1 .

Alternative hypothesis $\left(\mathrm{H}_{1}\right)=$ the variance ratio of actual volume from field and predicted volume from model was not equal to 1 .

F-test between variance of actual volume and predicted volume obtained from R-studio programme i.e. $(\mathrm{p}=0.1542)$.

Data: Volume (Vm3) actual and volume (Vm3) predicated

$\mathrm{F}=0.92545, \quad$ nominator $\mathrm{df}=49, \quad$ denominator $\mathrm{df}=49, \quad$ p-value $=0.7873$

Alternative hypothesis: true ratio of variances is not equal to 1

95 percent confidence interval: $0.5251682 \quad 1.6308091$

Ratio of variances: 0.9254453 
The p-value obtained from F-test was p $(0.7873>0.05)$ at 95 percent level of confidence. So, Null hypothesis $\left(\mathrm{H}_{0}\right)$ was accepted and alternative hypothesis $\left(\mathrm{H}_{1}\right)$ was rejected, thus the model (Model 5) was now eligible to crosscheck using Z-test for its prediction of tree volume as the variance were similar.

Paired Z-test was done between actual volume and predicted volume from model 5 at 95 percent significance level. Assumed hypothesis to test significance difference between actual volume and predicted volume is as under:

Null hypothesis $\left(\mathrm{H}_{0}\right)=$ There was no significance difference between actual volume from field and predicted volume from model.

Alternative hypothesis $\left(\mathrm{H}_{1}\right)=$ There was significance difference between actual volume from field and predicted volume from model.

\begin{tabular}{|llccccc|}
\hline & & & & & & \\
Minimum & 1st Quadrant & Median & Mean & 3rd Quadrant & Maximum & Z-score \\
0.2578 & 0.2578 & 0.2578 & 0.2578 & 0.2578 & 0.2578 & -1.1316 \\
\hline
\end{tabular}

The $\mathrm{p}$-value obtained from Z-test was $\mathrm{p}(0.2578>0.05)$ at $95 \%$ level of confidence. So, $\mathrm{H}_{0}$ was accepted and $\mathrm{H}_{1}$ was rejected, thus the model (Model 5) was successful in predicting tree volume.

\section{Discussion}

In this paper, we used previous research to reconstruct a stand volume estimation model compared with the best previous volume model for black locust trees (Robinia pseudoacacia $\mathrm{L}$.), the precision of this research model is higher because $\mathrm{R}^{2}$ value is more than double.

Redei and Veperdi (2001) provided an important relationship between the timber volume and the crown variables of black locust (Robinia pseudoacacia L.) for large-scale volume estimation. But in this paper, we have the timber volume and the crown area of Dalbergia sissoo stand in plantation area of 15-20 years old to estimate the stand volume.

Redei and Veperdi (2001) experimented and found the relationship between crown length and timber volume polynomial and the tree volume increases slow with increasing crown length but with further increase in crown length, the volume is seen to increase at higher rate. The correlation is marked $\left(\mathrm{R}^{2}=0.4114\right)$ for crown length and timber volume relationship. The equation derived between crown length and timber volume relationship for black locust was volume $=\mathrm{A}-\mathrm{B} *$ Crown $+\mathrm{C}^{*}$ Crown ${ }^{\wedge}$. Trees with a small crown projection area $\left(\leq 4 \mathrm{~m}^{2}\right)$ had the relatively highest volume performance, as depicted in figure 14.

This study proposed the volume model i.e. Volume $=\mathrm{A}^{*}$ Crown^ $2+\mathrm{B}^{*}$ Crown $+\mathrm{C}$. The $\mathrm{R}^{2}$ value of this model is 0.9125153 which seems more accurate than the above comparative model. Three model parameters i.e. A, B, C are used in the model and its values are: $\mathrm{A}=-0.0009909698, \mathrm{~B}=$ 0.0622226775 and $\mathrm{C}=-0.1911758529$, respectively. The relationship between tree volume and crown area is polynomial. The trend of this model exhibits that rate of volume distribution varied 
in direct proportion with increasing extent of crown area but with further increase in extent of crown area the rate of volume distribution shows inverse relationship (Figure 8).

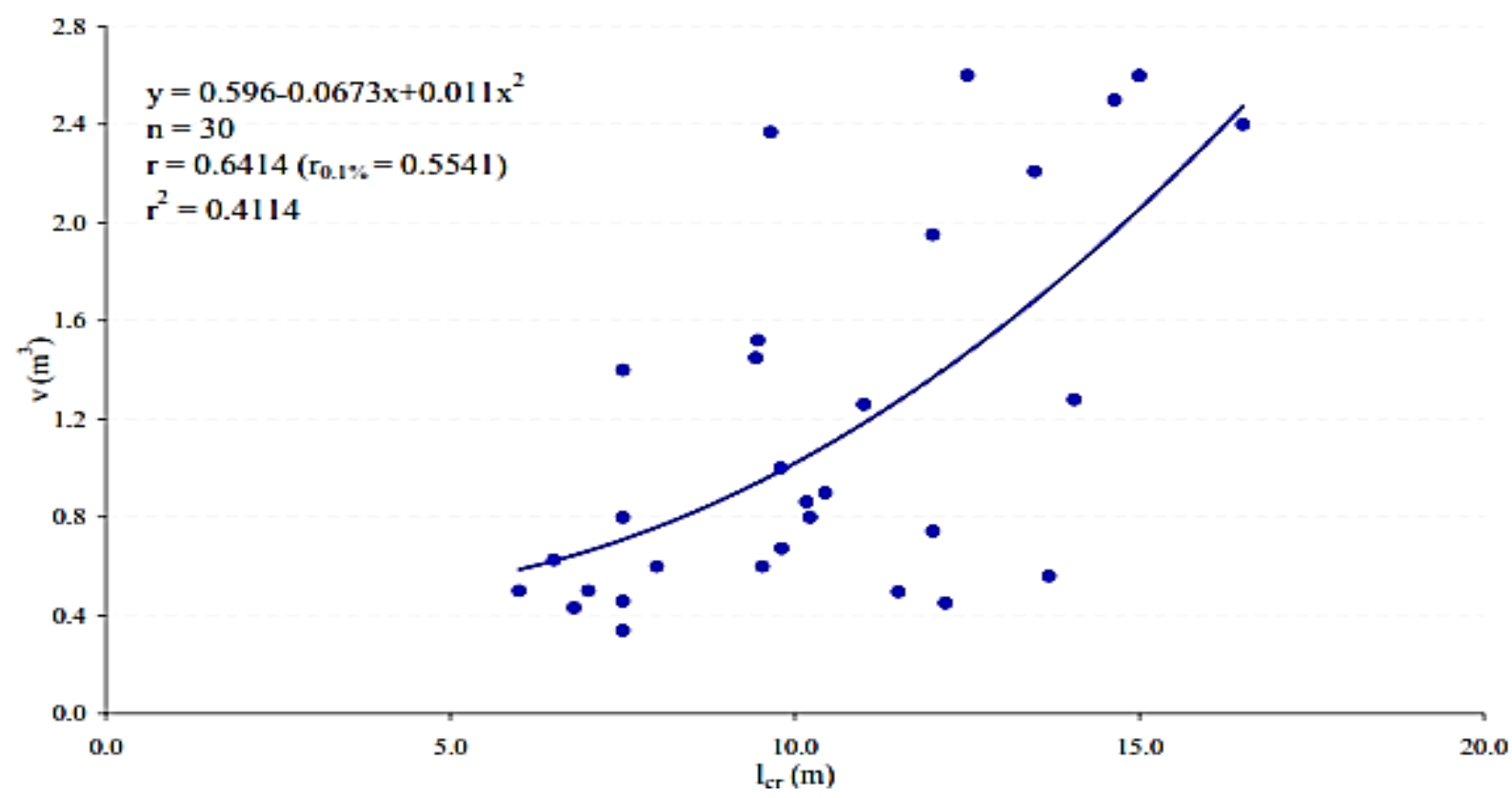

Figure 14: Relationship between crown length $(l c r)(m)$ and timber volume $(V)$

\section{Conclusion}

The research results revealed that the new best fitted model of tree volume against crown area for Dalbergia sissoo stand in plantation of 15-20 years of old. Depending on the degree of accuracy pursued, crown and value of three model parameters, i.e. A, B, C are combined together to produce the best tree volume model equation i.e. Volume $=A^{*}$ Crown ${ }^{\wedge}+B^{*}$ Crown $+C$. The Coefficient of Determination $\left(\mathrm{R}^{2}\right)$ value of this model is 0.9125153 and Root Mean Square Error (RMSE) is 0.054. The values of three model parameters are $\mathrm{A}=-0.0009909698, \mathrm{~B}=0.0622226775$ and $\mathrm{C}=$ -0.1911758529 . Thus, this model can be used to predict the tree volume for Dalbergia sissoo stand of 15-20 years old plantation forest. This model will help the manager, planners, users and decision makers for better management and utilization of Dalbergia sissoo forest in a long run.

\section{References}

Chourasia, S. (2012). Carbon sequestration study on Dalbergia Sissoo planted in different geometry. MSc Thesis, JNKVV, Jabalpur, India. p.83.

Eerikainen, K. (2010). Justification and best practices for collecting stem and tree analysis data for modelling purposes in Nepal. Forest Resource Assessment (FRA) in Nepal. Draft technical note complied in collaboration with the Institution Cooperation Instrument (ICI) project "Improving Research Capacity of Forest Resource Information Technology in Vietnam and Nepal". 16p+ Appendices. 
Gill, S.J., Biging, G.S. and Murphy, E.C. (2000). Modeling conifer tree crown radius and estimating canopy cover. Forest Ecology and Management, 126 (3): 405-416.

GOFC-GOLD (2011). A sourcebook of methods and procedures for monitoring and reporting anthropogenic greenhouse gas emissions and removals caused by deforestation, gains and losses of carbon stocks in forests remaining forests, and forestation. Global Observation of Forest and Land Cover Dynamics (GOFC-GOLD) Project Office, Natural Resources Canada, Alberta, Canada. 203 p.

Hatch, C.R., Gerrard, D.J. and Tappeiner, J.C. (1975). Exposed crown surface area: A mathematical index of individual tree growth potential. Can. J. For. Res., 5: 224-228.

Menwig, R.O., Miller, E.L. and Budy, J.D. (1979). Estimating pinyon and juniper fuels and biomass from aerial photographs. USDA For. Serv. Res. Note INT-RN: p.274.

Popescu, S.C. (2002). Estimating Plot-Level Forest Biophysical Parameters Using Small-Footprint Airborne Lidar Measurements. PhD Thesis, Virginia Tech, Blacksburg, USA, p. 155.

Redei, K. and Veperdi, I. (2001). Study of the relationships between crown and volume production of black locust trees (Robinia pseudoacacia L.). Lesn. Cas. - Forestry Journal, 47(2): 135-142.

Singer, M.T. and Lorimar, C.G. (1997). Crown release as a potential old growth restoration approach in northern hardwoods. Canadian Journal of Forest Research, 27(8): 1222-1232. 